Meta

Journal des traducteurs

Translators' Journal

\title{
Terminotics of the Future: Three Scenarios
}

\section{Thomas Schneider}

Volume 32, numéro 2, juin 1987

Vers l'an 2000. La terminotique, bilan et prospectives

Objectives: Year 2000 Terminotics. State of the Art, Prospects for the

Future

URI : https://id.erudit.org/iderudit/004047ar

DOI : https://doi.org/10.7202/004047ar

Aller au sommaire du numéro

Éditeur(s)

Les Presses de l'Université de Montréal

ISSN

0026-0452 (imprimé)

1492-1421 (numérique)

Découvrir la revue

Citer cet article

Schneider, T. (1987). Terminotics of the Future: Three Scenarios. Meta, 32(2),

205-211. https://doi.org/10.7202/004047ar d'utilisation que vous pouvez consulter en ligne.

https://apropos.erudit.org/fr/usagers/politique-dutilisation/ 


\section{TERMINOTICS OF THE FUTURE : THREE SCENARIOS}

THOMAS SCHNEIDER

Terminology and Linguistics, Siemens AG, München

Trying one's hand at prophesy can be quite lucrative, provided one isn't suffciently deterred by moral scruples to expound on the likely fate of millions of home journal readers for the next week.

Of course, what's good for the astrological goose is good for the economic gander. Only the public's rapid loss of memory has saved many a forecaster of currency exchange rates or the price of crude oil from ridicule.

By contrast, the realm of Science Fiction, even though incorporating some elements of prophesy of the astrological kind, does offer more than nebulous predictions. Serious Science Fiction literature will not merely dazzle the suburban, office-dwelling reader with a flamboyant display of highest-tech gadgets and the (of course victorious) fighting of Star Wars in typical B-grade movie cowboy style.

Thoughtful Science Fiction will usually try to anticipate problems before they have appeared in the consciousness of the average-informed reader. Extrapolating scenarios from a non-homogeneous present and projecting them into a different timeframe with different technological possibilities offers the Science Fiction writer a chance to playfully try out solutions. Assuming an unusual or not yet real environment, he is free to manipulate actors and available technologies to suit the legitimate purpose of suggesting solutions for envisioned conflicts. Unfortunately, the genre is also tempting for the not so skilled writer because the constraints of reality can be elegantly ignored.

In the following, let us try to weigh the lure of the singular description of the Golden Age and the equally enticing lure of singular imitation of Cassandra. The description of Terminotics for the next generation seems to require more than the spectrum of a rainbow. Prophesy will have to remain the forte of professional forecasters but perhaps some inferences can be drawn from three scenarios, each describing some possible aspects of the future of terminology work and of multilingual communication in general.

\section{SCENARIO I : THE ABSOLUTE RULE OF COST-BENEFIT}

Unfortunately, terminology work does not come for free. It takes highly qualified persons and a lot of resources, not to mention cooperative attitudes. Therefore changing priorities can easily unsettle the whole field. Let us assume that in conventionally structured economic systems, lack of resources because of high unemployment and lack of demand for consumer goods because of market saturation (three toasters in every household...) lead to the viscious cycle of a chronic economic recession if not a longterm depression.

"Strong men" enter the stage in more than one country. Simplistic solutions and patriotic buzz-words are in. Cost-benefit analyses by bookkeepers reveal that there is no material gain to be derived from things cultural, except for propaganda purposes. Several countries come to the conclusion that UNESCO, dominated by imagined political adversaries, is an expense which they cannot carry any longer - priorities have shifted, 
more stifling than ever before, to the military. One needs to prepare for the struggle over the ever smaller pieces of the cake. UNESCO is dissolved, Infoterm is inoperative because of lack of funds.

Moreover, the redirection of resources and attitudes in the Western industrialized countries has other, serious effects : the gap between the First World and the Third World is widening. Increasing economic pressures support the rise of local strong men in many a developing country elbowing their way ahead at the expense of others. Social Darwinist attitudes become popular, and the power of industrialized countries over disunited developing countries becomes excessive. Ever since the decreasing oil price has reduced the OPEC countries to the status of economic have-nots, political and economic expediency has enabled Western leaders to ignore requests by Third World countries for technology transfer. The first thing to be discontinued under industry's austerity measures is the expensive translation of technical documentation. "We cannot finance the learning process of the Third World ; they are going to have to finally work for themselves" says one prominent politician amidst the cheers of tens of thousands of people (who of course have not been told any better but who applaud the idea that they no longer have the responsibility to share their relative wealth with less fortunate people or those of a differing conviction). The egotistical Rambo is supported by the masses.

Popularity always leads to an imitation of the idol, and the government's and the economic strong boys' deceitful speech infiltrates the general language. The infamous creation of the term Entsorgungspark with the connotation of "lay down your cares in a green park" for a garbage dump for highly poisonous radioactive material is just a weak forewarning of things to come. Poor naive George Orwell, it is much worse than you ever feared. No, it is not that the ever present television advertising sells ordinary butter as "cream butter" or greasy hamburger meat as "chopped steak" or defines low prices as "quality", and it is not that Hollywood produced movies are (beyond the fact that Rambo with the white hat always wins) cliche-ridden and politically motivated.

It is worse. The one in power, in excessive power, does not even care if the other, lowly, person understands him. The ultimate machismo of Godfather Marlon Brando, mumbling his words without regard for any listener, has taken hold. A position of power is one in which one doesn't have to care if the listeners receive the message or not. It is the listener's problem. Communication on a partner level has become irrelevant, has become the victim of economic and political suppression. If developing countries desire a knowledge of the technology they have to buy, they are forced to export their brightest to learn in the supplier country. The brain drain worsens ; the need for economic and linguistic cooperation can be safely ignored since the recipient country doesn't have an elite to speak of anymore. No more need for multilingual terminology. Economic blackmail : "Learn our language, or forget about technological progress."

Of course, "our language" has suffered from the predominance of military and advertising abuse, too. Whether we use "verb" forms like develop, developize, development or developmentize without any semantic distinction does not matter. As long as in the listener the appropriate emotional appeal is aroused, all intended goals are achieved. Who needs precision, critical appraisal, definition ?

Since the need for multilingual communication has vanished due to a newlyfound economic imperialism and nationalist attitudes, potential markets for multilingual word-processing have also shrunk. The large terminology data banks have long folded because economic pressures have forced them to charge cost-covering prices to their users which these users have not been able to pay - because of economic pressures. 
If terminology work is done at all, it is done "cost-effectively", that is, by low-paid persons without linguistic or subject matter competence, without regard to coherence, subject matter validity or multilingual application, ad hoc, without any attempt at standardization or agreement with others. The book-keepers say it is cheaper that way.

The occasional maverick still manages to draw money from the militaryindustrial complex for the development of a strategically useable terminology data base. But of course, the new Rambo attitude requires that the wheel be reinvented and not be compatible with anything else. Needless to say, these amateurish provincial ventures are doomed to failure. No cooperation, no viable terminology, no communication.

In the field of medicine, the problem of multilinguality is solved in an analogue fashion : papers are accepted in English only ; no more French, German, Italian or Russian. Consequently a whole field is reduced to non-information. Researchers struggle to write their papers in school English, as best as they can, and have them rejected by the leading journals, on account of their linguistic shortcomings. Valid research is ignored. The fact that significant amounts of work are unnecessarily being duplicated is not obvious to monolingual book-keepers doing the cost-benefit analyses for proposed new research projects. It doesn't show up in any debit column.

The academic Europe's futile protests cannot compete with simple solutions based on cost-benefit analyses. Hard-pressed by economic factors of high unemployment and excessive spending on military matters, the last remaining bastions of critical thought, the teaching of philosophy, literature and similar topics of economic nonbenefit are no longer supported except by the occasional retired industrialist with guilt feelings.

One may ask : where is terminology in all this ? It isn't. Priorities have changed to favor an excessive emphasis on quantifiable economic and military profit so that the ideal of cooperation and fruitful communication is considered expendable, is disqualified as an expensive dream. Egotism in its worst form has all but eradicated attempts at improving communication. Yes, technological advances will have made the existence of large terminology databases on a PC or even a calculator possible - but it has become irrelevant. Who needs a definition when he can rule with a deadly laser gun ?

\section{SCENARIO II : THE RULE OF REASON}

If scenario I seemed like a substandard instantiation of 1984 , we could try something more cheerful for contrast. Springtime, birds, flowers and bees find their counterparts both in insight and in technological advances.

Of course, insight has not come out of the blue. It has taken a major accident in a civilian nuclear power plant for leaders of the world to realize that radioactive fall out does not stop for official inspection at borders, and that proclaiming the notion of a nuclear deterrent of one country against another should immediately qualify the holder for a safe cell in the high-risk block of a well-guarded institution. Since the change in attitude has become prevalent in all major powers, disarmament talks are finally successful. And, ode to joy, billions of dollars are freed for other, more productive causes.

Finally there is money to build adequate infrastructures in Third World countries, with the effect that new markets for peaceful high-tech industrial products are created. There is money for advanced education, with the effect that more progress is made in advanced research in many fields. There is money for the arts and leisure time for people to enjoy them. And after it has finally dawned even on hardliners in East and West that the World's greatest and only hope lies in cooperation and improved communication, both scholarly and financial support is given to the field.

One of the first areas to benefit is foreign language instruction in schools, universities and industry. By necessity, the field of terminology - being indispensable for error- 
free communication, especially in translation - follows. Infoterm is elevated to the status of a prominent UNESCO department in which several hundred qualified employees are charged with the task of coordinating all terminological activities in the world.

EURODICAUTOM, TERMIUM, BTQ, LEXIS and TEAM have created standardized interfaces between their record definitions so that information can be freely exchanged. And it is exchanged. The already tested division of labor has proved so successful that it is extended. Languages and subject areas are divided up according to the expertise of the terninologists and partners associated with the banks. And increasingly, industry becomes involved in the process of creating and standardizing terminology too. The change in technology, away from an emphasis on hardware and machinery to abstract problem-solving techniques like software and game plans, and the change in attitude, away from a seller-buyer relationship to a cooperative partnership, have increased the need for detailed documentation - and the need for unambiguous multilingual terminology.

The introduction of ISDN systems has improved the exchange of information dramatically so that terminology research is no longer an expensive island. The result of an individual's work can be immediately forwarded to one of the large banks and shared by others. Of course, it has taken a long time to define the quality criteria for multilingual terminology, but the new spirit of cooperation has brought terminologists together, and new, specialized banks have avoided the lure of reinventing the wheel. They too have chosen concept-based approaches and have also ensured their formal compatibility with existing banks.

With the new emphasis on things linguistic, new tools become available for the terminologist and translator. The hardware basis for most of the work is a portable desk-top PC, moderately priced, with several parallel processors able to run different operating systems. While one handles sophisticated word processing on a UNIXgrandson, another does text analysis, pretending to be a full-fledged LISP or PROLOG machine. Knowledge bases are queried with a new generation language, also incorporated in a chip. A separate processor takes care of data communication, to and from the network.

Processor speed has increased greatly to surpass that of the CRAY mainframes of 1985, and the limitation of memory is no longer a problem. Whereas in 1985 a PC was hard pressed to hold more than $20 \mathrm{MB}$, a memory of several gigabytes is now no longer an exception on a cheap PC. All PCs are constructed in such a way that via a standardized interface, new modules containing loaded memory or robust programs can be plugged in. It is only for the convenience of handling that these cartridges are kept to the size of a cigarette box ; several megabytes of stored information would easily fit into the volume of an old-fashioned eraser.

Britten-Lee machines to sort through extremely large corpora of texts are available as plug-in software modules for one of your PC's processors. The terminologist can compare any text with his own database ; the PC will print out any new term in its context. On the push of a function key, one of the processors will query sequentially one or all interconnected databases and display the present status. The quiet electronic printer, a faster and more silent follow-up to the laser printer, handles graphics, tables and a multitude of alphabets and does not disturb the peace of the home life.

Should the translator or terminologist require different fonts, they can be chosen from an extensive menu and modified - according to personal preference - simply by altering the dots on the 40 by 30 dot matrix displayed on the screen. Different alphabets appear on the keyboards as LCDs or as projections from a built-in light source, and 
pushing a function key is all that is needed to handle different scripts and writing modes in the same line. Going from right to left for fully vocalized Arabic and inserting French (left to right) is no longer a problem.

What in the distant past had been the sole domain of the large data banks implemented on main frames has become available on PC. Software packages permit input and syntactic checking of terminological data. They can be sorted alphabetically within each language, by subject field, source or date ; phrases can be found under key words. The terminological entries can be retrieved according to any criterion, be it by term, language, subject area, date of entry or any combination of criteria, in any format desired.

The small data bank system has almost all the functions of the large data banks except for large-scale lexicography and is linked to a sophisticated word processor. Pressing a function key will automatically initiate a search in the data base for the unknown word that has appeared in the middle of a text. Inflected forms are lemmatized based on an internal expert system that utilizes a set of morphological rules and inferences from a self-learning mechanism. If the queried term is missing in the small database, an incremental search pattern tries, on demand, the other data banks linked to the same network. The same program also handles global replace functions; its analysis module will interpret the syntactic context correctly and supply the appropriate morphological form.

Direct access via ISDN to enormous amounts of documentation, literature and knowledge bases permits effective work in the home environment. And since all colleagues are working on-line within the international network they can be reached from the desk-top PC for subject matter consultation. The weekly meetings at the office are not, strictly speaking, necessary from the viewpoint of work efficiency but serve the purpose of keeping social contact.

Ever since the significance of the standardization of multilingual terminology has been realized and funding has been made available, several thousand fully documented terms are added to the network of the large data banks each month. Whereas it is possible for individual users to query the millions of entries in one of the large banks, another possibility also exists. At regular intervals, updated modules of standardized terminology for specific subject fields are sent out to subscribers. The bubble-memory unit which plugs into the user's PC can hold several million terms, and is replaced with an updated version a month later.

While this is a read-only memory, additions produced by the terminologist working at home are written into a temporary file which is forwarded to the appropriate large data bank within the network. There, the entries are checked by the committee responsible for the subject field, for content and syntax, and are then entered into the large common pool. Immediately this user's work is available to all others. An automatic accounting system credits his account for his contributions. Thus, the incentive to contribute actively within the network is increased.

Research in the area of natural language processing has made significant progress. It is no longer necessary to sort through thousands of documents by hand to find the desired one, or to construct series of Boolean expressions. The user can now ask questions of the knowledge base in his own language, and an intelligent interface will interpret his questions. For the terminologist this means that hidden definitions of terms, buried in reams of literature, can be found by semantic content immediately. This constitutes probably the greatest advance in his tools.

Advances in the area of machine translation make it possible to also sort through vast quantities of foreign-language texts in search of elusive definitions. Cooperative at- 
titudes have led to the creation of very large subject-specific dictionaries for the automatic translation of texts. Grammar rules adapt automatically to the type of text involved. Within minutes, the machine-readable texts can be scanned for the desired passages which are then output in a bilingual format. Differences in a term's definition from one language to another are more easily found.

Not only has the world finally recognized the great skills and intellect needed for the professions of terminologist and translator, but the changed status has also improved the social and financial position. This in turn has attracted persons with higher qualifications to the field. The effect on education and the media is noticeable. Foreign languages are no longer the step children of university education and the media, but being able to work in several languages has become a necessity for anyone intending to enter a university. TV and Press have become aware of how many political misunderstandings are happening because of sloppy translations by overtaxed journalists. From now on, TV and press correspondents are required to have a full-fledged translator's training before they are allowed to file a report from abroad.

And the World lived happily ever after.

\section{SCENARIO III : THE SLOW UPHILL STRUGGLE}

A more likely situation might be the following : the large data banks will continue to exist, even though there will be ups and downs because of financial feast or famine. Constant publicity work by organizations like Infoterm and others, however, has created enough public awareness of the question of multilingual terminology that the work in itself and the necessary tools are no longer seriously questioned.

Further development of the technical structure of the large banks, however, will not be pursued because it is felt that the current structures are difficult enough to maintain. Rather, to incorporate features like graphics, simplified solutions are sought such as keeping a field in the record free for a pointer to an entry in a specialized graphics store on a different system. This would of course be less convenient than having all these features integrated within a single system but it is a cheaper solution that terminologists can live with.

Some of the large banks will definitely standardize their interface and work on achieving a compatible classification system so that data can be exchanged freely. One remaining problem will be the question of copyright. When is a term the "property" of its creator and when does it belong to the public domain ? What happens if an existing bilingual entry is enlarged to contain another three foreign-language equivalents ? Can sets of technical terminology be treated like general language corpora where the addition or deletion or change of a percentage of the entries may constitute a new copyright ? These issues will have to be addressed before viable systems of information exchange that go beyond a merely bilateral agreement can be implemented.

Some of the large banks may not want to standardize along with the others, feeling that their material is either too confidential or too idiosyncratic to be exchanged, and will therefore not invest substantial funds in such work. Nevertheless, consultations between the large banks should probably continue on a more or less regular basis so that at least within this group the effects of new developments and changes in one of the banks will be discussed. In all probability, new banks will be set up. Some of them will be legitimate establishments for special purposes and narrow applications ; others however will be designed mainly for prestige purposes, and that implies : be different from the other banks, and incompatible. If each man is an island, a term bank shouldn't be, but it seems a hopeless task to keep superfluous projects from starting up if egos are involved. 
The world of data processing will move away from the use of time-sharing mainframes to integrated networks of specialized servers and multiprocessor PCs. ISDN systems improve the transfer of data, and both storage capacity and processing speed on PCs become adequate for the handling of even large amounts of data. Keeping large sets of multilingual terminology on-line will not be a problem, and specialized functions like concordance programs, spelling checkers or automated dictionary look-up should be commonplace.

As with the large banks, the problems will not be on the technical side but in the area of organization. How are the modes of updating, standardizing and revision to be implemented, in a manner that makes everything available to everybody immediately, that avoids redundancy and ensures the appropriate quality standard ? How can the tedious process of standardization on an international scale be organized, funded and carried out effectively? As in the area of copyright, a lot of detailed consideration and cooperation will be necessary.

The main danger in the new capabilities of small computers lies in the fact that an individual has all the tools at hand to work by himself. Of course, autonomy per se is nothing negative. But it is enticing, as many years of translation work in larger offices have proven, to keep one's knowledge to oneself and to disregard the work of others. The consequences, i.e. an abundance of pseudo-synonyms and the creation of terminological garbage, show that more efforts have to be made to shape cooperative attitudes in all persons associated with the field, be they translators, terminologists, researchers or teachers.

And of course, this attitude of cooperation cannot stop at the edge of a small circle; it has to go beyond national and linguistic boundaries. Economic competition in the negative sense and nationalist attitudes have to be replaced by a symbiotic approach, but this will probably be the most difficult to achieve.

All the technical tools required for adequate terminology work, for generation, retrieval and dissemination will be available. The theoretical foundation for terminology work has been laid. So for terminotics proper, there should be a reasonable future. However, terminology and terminology work do not exist in a vacuum. Economic considerations, priorities within industry and on the political level have significant effects on the field. So in order to achieve the appropriate basis and framework for effective and efficient terminology work, there must be more efforts towards convincing individuals and governments of the benefits of cooperation on all levels and a substantial redefinition of international relations. 